\title{
Life-threatening hypoglycemia resulting from a non-islet cell tumor
}

\author{
Nirosshan Thiruchelvam, MD, ${ }^{a}$ Gaurav Kistangari, MD, MPH, ${ }^{\mathrm{b}}$ Catherine Listinsky, MD, \\ Hamed Daw, MD, ${ }^{\mathrm{d}}$ and Vikramjeet Kumar, MD
}

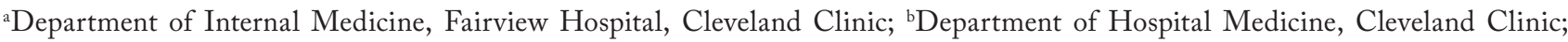
'Department of Pathology, Case Western Reserve University; ${ }^{\mathrm{d}}$ Moll Cancer Center, Cleveland Clinic; and ${ }^{\mathrm{e} D i v i s i o n}$ of Endocrinology, Fairview Hospital, Cleveland Clinic, Cleveland, Ohio
\end{abstract}

$\mathrm{N}$ onislet cell tumor-induced hypoglycemia (NICTH), also known as Doege-Potter syndrome, is a rare paraneoplastic syndrome seen in association with various nonpancreatic tumors, benign and malignant, and comprising mesenchymal, vascular, or epithelial cell types. We report a case of recurrent life-threatening hypoglycemia from a large pelvic solitary fibrous tumor.

\section{Case presentation}

A 70-year-old woman was brought to the emergency department after being found unresponsive at home by paramedics. When paramedics arrived at her home, her bloodglucose level was low, $23 \mathrm{mg} / \mathrm{dL}$ (normal, $>70 \mathrm{mg} / \mathrm{dL}$ ). She received a dose of intravenous dextrose that improved her blood glucose level. She had had a similar episode of severe hypoglycemia a week earlier that had also resolved after intravenous dextrose. The patient also complained of lower abdominal pain of 6 months duration. Her past medical history included hypertension and congestive heart failure that were well controlled with medications. She was not diabetic and said she had not consumed any hypoglycemic medications or insulin. A physical examination revealed a pelvic mass, the size of a 12-week pregnant uterus, on bimanual examination. Her complete blood count, comprehensive metabolic panel, and liver function tests were normal except for the low blood glucose.

A further hypoglycemia workup revealed a low C-peptide level $(0.1 \mathrm{ng} / \mathrm{ml}$ [normal, $0.8-3.5 \mathrm{ng} / \mathrm{ml}]$ ), low insulin levels ( $<1 \mathrm{uIU} /$ $\mathrm{ml}$; [normal, $<3 \mathrm{uIU} / \mathrm{ml}]$ ), negative oral hypoglycemia agent assay, negative insulin antibody screen, and a serum cortisol level of $21 \mathrm{ug} / \mathrm{dL}$ (normal, 3.4-26.9 ug/dL). A computer-tomography scan of the abdomen with contrast revealed a large pelvic mass $(20 \times 13 \times 14$ $\mathrm{cm}$; Figure 1). Because of our concerns about her possibly having NICTH, we measured her levels of insulin-like growth factor IGF-1(10 ng/ml [nor$\mathrm{mal}, 54-205 \mathrm{ng} / \mathrm{ml}])$ and IGF-2 $(560 \mathrm{ng} / \mathrm{ml}$ [nor$\mathrm{mal}$, 288-736 $\mathrm{ng} / \mathrm{ml}])$. Her IGF-2/IGF-1 ratio was $>3: 1$, which was suggestive of NICTH.

An exploratory laparotomy revealed the pelvic mass with prominent vascularity, so surgical resection was not performed to avoid increased risk of bleeding, and a biopsy of the mass was done with caution. Following the biopsy, a histopathologic diagnosis of spindle cell neoplasm was made. The features were most consistent with solitary fibrous tumor (Figure 2), which further confirmed the diagnosis of NICTH secondary to a large pelvic solitary fibrous tumor. Subsequently, the patient was started on oral prednisone $20 \mathrm{mg}$ daily that prevented further hypoglycemic episodes. Although she was sent

Accepted for publication November 12,2014. Correspondence: NirosshanThiruchelvam, MD; thirucn@ccf.org. Disclosures: The authors have nodisclosures. JCSO 2015;13:296-297. (02015 Frontline Medical Communications.DOI 10.12788/ jcso.0163. 
home for possible future tumor resection with curativeintent, she continued to refuse surgical resection. At 1-year follow up her prednisone dose was titrated down to $5 \mathrm{mg}$ daily without any further hypoglycemia.

\section{Discussion}

NICTH is a paraneoplastic syndrome often associated with predominately large tumors of mesenchymal origin in the chest, abdomen, and pelvis. The pathophysiology involves the overproduction of an abnormal IGF precursor molecule, known as high-molecular weight IGF or the "big" IGF that exerts insulin-like effects such as hypoglycemia and hypokalemia. ${ }^{1} \mathrm{NICTH}$ is characterized by recurrent fasting hypoglycemia. ${ }^{2,3}$ The diagnosis of NICTH should therefore be considered in patients presenting with unexplained hypoglycemia, especially after other common causes such as medications, multi-organ failure, and hyperinsulinism syndromes have been excluded.

The typical laboratory abnormalities associated with NICTH include hypoglycemia, low serum insulin and $\mathrm{C}$-peptide levels, a negative oral hypoglycemia agent assay, low growth hormone levels, and an elevated IGF-2/IGF-1 ratio greater than the normal 3:1.1 Resection of the tumor is often curative of NICTH, but if resection is not possible or delayed, as was the case with our patient, then the management includes continuous glucose or glucagon infusions in the acute care settings; and corticosteroids, ${ }^{3}$ diazoxide, glucagon, and recombinant human growth hormone or octreotide for chronic recurrent hypoglycemic episodes. ${ }^{1}$ Glucocorticoids may be of greater benefit as chronic therapy because they increase blood glucose levels by suppression of tumor production of IGF-2. ${ }^{4}$

In conclusion, unexplained hypoglycemia should prompt clinicians to exclude NICTH as a possible etiology of

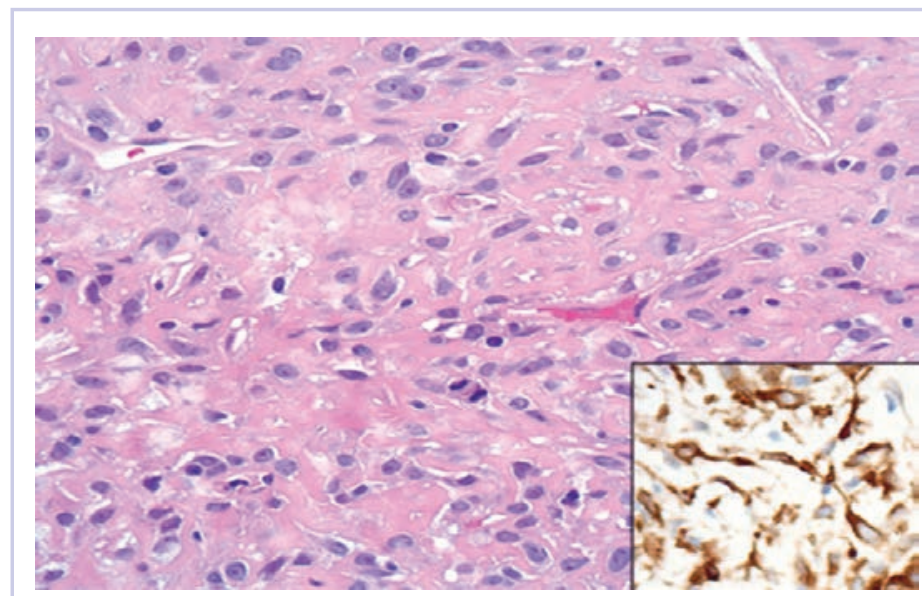

FIGURE 2 The results of a core biopsy showed features of a solitary fibrous tumor, consisting of bland spindled to ovoid cells in a collagenous background. Thin-walled branching vessels are noted in the background on H\&E. Inset, Tumor cells are positive for $\mathrm{Bcl}-2$ protein by immunohistochemistry.

recurrent hypoglycemia in patients with or without an established diagnosis of malignancy.

\section{References}

1. Bodnar TW, Acevedo MJ, Pietropaolo M. Management of non-isletcell tumor hypoglycemia: a clinical review. J ClinEndocrinolMetab. 2014;99:713-722.

2. de Groot JW, Rikhof B, van Doorn J, et al. Non-islet cell tumour-induced hypoglycaemia: A review of the literature including two new cases. EndocrRelat Cancer. 2007;14:979-993.

3.Fukuda I, Hizuka N, Ishikawa Y, et al. Clinical features of insulinlike growth factor-II producing non-islet-cell tumor hypoglycemia. Growth Horm IGF Res. 2006;16:211-216.

4. Teale JD, Marks V. Glucocorticoid therapy suppresses abnormal secretion of big IGF-II by non-islet cell tumours inducing hypoglycaemia (NICTH). Clin Endocrinol (Oxf). 1998;49:491-498. 